\title{
Simultaneous degradation of phenol and 3-chlorobenzoate by a mixture of separately immobilized cells of two strains of Pseudomonas - A preliminary study
}

\author{
Aneez Ahamad Padippurathundil Yossouff and Mohammad Kunhi Anebagilu Abdulla*
}

\author{
Department of Food Microbiology, Central Food Technological Research Institute, Mysore-570 013, India \\ E-mail: kunhiaam@yahoo.com; aamkunhi@gmail.com
}

Received 30 December 2010; received in revised form 19 May 2011; accepted 24 May 2011

\begin{abstract}
Simultaneous degradation of halogenated and non-halogenated aromatic compounds that are catabolised through different cleavage pathways is generally difficult due to biochemical incompatibility. However, free cells of a mixed culture of Pseudomonas sp. CP4 that degrades phenol through meta-pathway and Pseudomonas aeruginosa strain $3 \mathrm{mT}$ that degrades 3-chlorobenzoate through ortho-pathway was shown, earlier, to degrade mixtures of phenol/cresols and 3-chlorobenzoate in shake flasks. In the present study the degrading efficiency of these strains when immobilized (separately) in Ca-alginate gel beads was tested using a fluidized bed reactor. Complete mineralization of up to $5 \mathrm{mM}$ equimolar mixture of phenol and 3-chlorobenzoate was observed when the beads were used at 1:1 ratio. From a $10 \mathrm{mM}$ equimolar mixture although phenol was completely mineralized 3-chlorobenzoate degradation was not complete as evidenced by accumulation of some intermediary metabolites and the release of only $86 \%$ of inorganic chloride ( $\mathrm{Cl}^{-}$). Degradation rates of both the compounds by the immobilized cells, in general, were far better than that by the free cells. With further studies to select suitable gel matrices and optimization of bioreactor conditions these strains can be effectively deployed for treatment of heterogeneous aromatic wastes.
\end{abstract}

Keywords: immobilized Pseudomonas cells; phenol; 3-chlorobenzoate, co-degradation

\section{INTRODUCTION}

Phenols, chlorobenzoates and other aromatics are generated by various chemical and pharmaceutical industries as well as through partial degradation of certain insecticides and herbicides and also occur naturally. They contribute a formidable bulk to the environmental pollution and have tremendous adverse effects on the biota and need to be eliminated (Chaudhry and Chapalamadugu, 1991; Ajith-Kumar and Kunhi, 1997; Agarry et al., 2008; Basha et al., 2010). Processes based on microbial degradation are generally preferred for elimination of these toxic chemical pollutants because of their lower operational costs and the possibility of complete mineralization as against conventional treatment technologies (Vidali, 2001; Brar et al., 2006). The biodegradation pathways of most of the aromatic compounds generally converge at a dihydroxy ring compound such as catechol, protocatechuate, gentisate or their derivatives which is then cleaved by a dioxygenase (Dorn and Knackmuss, 1978; Bartels et al., 1984; Ajith-Kumar and Kunhi, 1997). Generally, chlorocatechols are cleaved by catechol 1, 2-dioxygenase (C12D, pyrocatechase II) through a modified ortho-mode (Chaudhry and Chapalamadugu, 1991; Fetzner, 1998; Ajith-Kumar and Kunhi, 2000), though a few exceptions have been reported (Kaschabek et al., 1998). Nonhaloaromatics such as phenol, benzoate, cresols, methyl benzoates etc., on the other hand, are usually degraded by bacteria through a meta-fission pathway involving catechol 2, 3-dioxygenase (C23D, meta-pyrocatechase) (Agarry et al., 2008; Basha et al., 2010) although there have been reports, in recent years, on the involvement of C12D in the catabolism of phenol (Ahamad and Kunhi, 1996; Agarry et al., 2008; Basha et al., 2010).

Most bacteria are not capable of degrading chloroand non-chloroaromatics simultaneously due to metabolic incompatibility. Inhibition of the meta-ring cleaving enzyme C23D (Bartels et al., 1984) or the reduction in the rate of $\mathrm{C} 12 \mathrm{D}$ reaction in the presence of chlorocatechols, particularly of 3-chlorocatechol (3-CC) (Dorn and Knackmuss, 1978) has been shown to be the reason for this failure. Various techniques such as use of hybrid and mutant strains, and cloned organisms have been tried to circumvent these metabolic bottlenecks for degrading mixtures of halo- and non-haloaromatics simultaneously (Chaudhry and Chapalamadugu, 1991; Franck-Mokroß and Schmidt, 1998). All these strains, which operate through a modified ortho-pathway, have limitations such as relatively low rates of degradation and inability to degrade relatively high concentrations of the substrates. More efficient degradation of high concentrations of mixtures of chloro- and non-chloroaromatics by mixed cultures of microbial strains that can degrade a high concentration of at least one of the compounds requires the use of mutually compatible strains. We have, earlier, demonstrated efficient degradation of 3-CBAphenol/cresols mixtures simultaneously by free cells of a two-membered mixed culture, in shake flasks, when added at appropriate inoculum and substrate ratios (Babu 
et al., 1995a). This mixed culture contained Pseudomonas sp. strain CP4 (CP4), which could degrade up to $1.5 \mathrm{~g} / \mathrm{L}$ of phenol (Babu et al., 1995b) and up to $2.0 \mathrm{~g} / \mathrm{L}$ of cresols (Ahamad and Kunhi, 1999; Ahamad et al., 2001) through meta-cleavage pathways and $P$. aeruginosa strain $3 \mathrm{mT}$ $(3 \mathrm{mT})$ capable of degrading $8.0 \mathrm{~g} / \mathrm{L}$ of $3-\mathrm{CBA}$ and $12 \mathrm{~g} / \mathrm{L}$ of 4-chlorobenzoate (4-CBA) via a modified ortho-pathway (Ajith-Kumar and Kunhi, 2000). A mixed culture of the strain $3 \mathrm{mT}$ and an ortho-pathway-following phenol degrader, Pseudomonas stutzeri strain SPC-2 (Ahamad and Kunhi, 1996) also degraded 3-CBA-phenol mixtures efficiently when used as free suspended cells in shake flasks (Jayachandran and Kunhi, 2009).

It has been well established that immobilization of the degrading organisms improves their efficiency and such systems have been exploited, during the last few decades, for elimination of a variety of pollutant chemicals (Keweloh et al., 1989; Cassidy et al., 1996). There have been several reports on degradation of phenol individually by several immobilized microbial systems (Agarry et al., 2008; Basha et al., 2010). Recently, we also have shown that tolerance to and degradation rate of phenol could be increased several-fold by immobilizing the cells of Pseudomonas sp. CP4 in both Ca-alginate and agar gel beads (Ahamad and Kunhi, 2011). However, there have been hardly few reports on degradation of chlorobenzoates using immobilized cell systems (Sahasrabudhe et al., 1991; Yun et al., 2009) and there seems to be no report at all on simultaneous degradation of phenol and chlorobenzoates by immobilized microbial systems. In the present communication we present some preliminary data on simultaneous degradation of equimolar mixtures of phenol and 3-CBA, in a fluidized bed reactor, by a 1:1 mixture of immobilized cells of strains CP4 and 3mT that were entrapped separately in Ca-alginate gel beads.

\section{MATERIALS AND METHODS}

\section{Chemicals}

Phenol (AR grade) procured from Qualigens Fine Chemicals, Bombay, India, was purified by distillation and was used immediately. 3-CBA was purchased from Sigma Chemical Co., Mo, U.S.A. Sodium alginate was purchased from Allied and Company, Bombay, India. Agar powder and the chemicals used in the culture media and reagents were of high purity and were procured from $\mathrm{Hi}$-Media Laboratories Pvt. Ltd., Mumbai, India.

\section{Microorganisms}

The two bacterial strains viz., Pseudomonas sp. CP4 (Babu et al., 1995b; Ahamad and Kunhi, 1999; Ahamad et al., 2001) and Pseudomonas aeruginosa 3mT (Babu et al., 1995a; Ajith-Kumar and Kunhi, 2000; Jayachandran and Kunhi, 2009) used in this study were the ones isolated in the laboratory previously.

\section{Preparation of cell biomass and entrapment in calcium alginate gel}

Cell biomass of strain CP4 was prepared by growing it in a $10 \mathrm{~L}$ fermenter ('Digi-Ferm fermenter', locally fabricated) as described previously (Ahamad and Kunhi, 2011) in a mineral medium (M3 medium) (Babu et al., 1995b) containing $500 \mathrm{mg} / \mathrm{L}$ of phenol. M3 medium contained: (g/L) $\mathrm{KH}_{2} \mathrm{PO}_{4}, \quad 2.72 ; \mathrm{Na}_{2} \mathrm{HPO}_{4}, \quad 5.0 ; \mathrm{NH}_{4} \mathrm{NO}_{3}, \quad 0.5$; $\mathrm{MgSO}_{4} \cdot 7 \mathrm{H}_{2} \mathrm{O}, 0.2 ; \mathrm{Ca}\left(\mathrm{NO}_{3}\right)_{2}, 0.1$; trace minerals solution, $1.0 \mathrm{~mL}$ [consisting of ( $\mathrm{g} / \mathrm{L}) \mathrm{FeSO}_{4} \cdot 7 \mathrm{H}_{2} \mathrm{O}, 1.0$; $\mathrm{MnSO}_{4} \cdot \mathrm{H}_{2} \mathrm{O}, 1.0 ; \quad \mathrm{Na}_{2} \mathrm{MoO}_{4} \cdot \mathrm{H}_{2} \mathrm{O}, 0.25 ; \quad \mathrm{H}_{3} \mathrm{BO}_{3}, 0.1$; $\mathrm{CuCl}_{2} \cdot 2 \mathrm{H}_{2} \mathrm{O}$ ]. The $\mathrm{pH}$ of the medium was maintained at 7.0. Strain $3 \mathrm{mT}$ was also grown similarly in the same mineral medium but with $3-\mathrm{CBA}$ (500 mg/L) as carbon source.

The cells of both the strains were harvested and washed and then immobilized by entrapment in $\mathrm{Ca}$ alginate gel separately as described previously (Ahamad and Kunhi, 2011). (The cells of the two strains were not co-immobilized in the same gel beads to avoid the likely problem of biochemical incompatibility that might arise due to close proximity). The cell-entrapped beads containing $2 \%$ alginate had an average diameter of $3 \mathrm{~mm}$ in both the cases.

\section{Degradation studies with Ca-alginate entrapped cells}

All the degradation experiments were carried out in a Gallenkamp modular fermenter (A. Gallenkamp and Co., London, UK) fitted with a $1 \mathrm{~L}$ capacity fermenter jar (bioreactor), air sparger, peristaltic pumps for drawing samples and for adding alkali or acid for maintaining $\mathrm{pH}$, if required (the setup of the bioreactor system is shown in Figure 1). M3 medium devoid of the buffering salts $\mathrm{KH}_{2} \mathrm{PO}_{4}$ and $\mathrm{Na}_{2} \mathrm{HPO}_{4}$ was used in all the experiments as these phosphates caused extensive disruption of the $\mathrm{Ca}$ alginate beads as described earlier (Ahamad and Kunhi, 2011). In the fermenter jar $500 \mathrm{~mL}$ medium was taken and $20 \mathrm{~g}$ (wet wt.) each of the Ca-alginate-entrapped cells of the two strains were suspended in it. Phenol and 3-CBA were added as the mixed substrates in required quantities

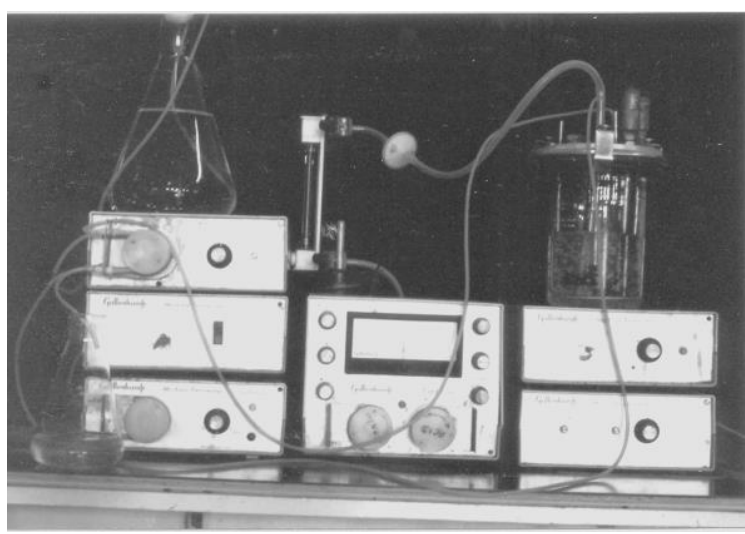

Figure 1: The experimental setup of the Gallenkamp modular fermenter used in the studies. 
such as 2, 5, and $10 \mathrm{mM}$ each. Sterile air was sparged from the bottom of the reactor jar through a sparger at a rate of $500 \mathrm{~mL} / \mathrm{min}$ (i.e. at $1 \mathrm{vvm}$ ) in all the experiments. Studies on the degradation of higher concentrations of the substrates i.e. 5 and $10 \mathrm{mM}$ equimolar levels were carried out in consecutive batches using the same beads that were inoculated to the previous batch of $2 \mathrm{mM}$ substrates, after washing them with the medium. Degradation of the substrates was followed by collecting samples of the culture broth at different periods and analyzing them for residual phenol, 3-CBA, free cell content, inorganic $\mathrm{Cl}^{-}$ released and intermediary metabolites.

\section{Quantitative determinations}

\section{Determination of cell biomass}

Cell biomass in the gel beads and the cells leached out to and grown in the medium were estimated in terms of total cell protein by the method of Lowry et al. (1951) as described previously (Ahamad and Kunhi, 2011).

\section{Determination of phenol concentration}

Phenol was estimated by the modified 4-aminoantipyrene colorimetric method of Lacoste et al. (1959).

\section{Determination of 3-CBA}

3-CBA was estimated by HPLC (Shimadzu LC10A) with a C18, reverse-phase column $(150 \times 4.6 \mathrm{~mm})$ using methanol/water/acetic acid (40:60:1, by vol.) at a flow rate of $1 \mathrm{ml} / \mathrm{min}$ and was detected by UV absorbance at 235/275 nm (Jayachandran and Kunhi, 2009).

\section{Determination of inorganic chloride}

Inorganic chloride $\left(\mathrm{Cl}^{-}\right)$released to the medium was estimated by the procedure of Bergmann and Sanik (1957) based on the principle of displacement of thiocyanate ion from mercuric thiocyanate by chloride ion, in the presence of ferric ion, as described by Jayachandran and Kunhi (2009).

\section{Determination of 3-chlorocatechol}

3-Chlorocatechol (3-CC) accumulated in the medium was qualitatively determined as described previously (AjithKumar and Kunhi, 2000).

\section{RESULTS}

Ca-alginate beads [20 g (wet wt.) each] entrapping separately the cells of strains CP4 and $3 \mathrm{mT}$ were inoculated into $500 \mathrm{~mL}$ M3 medium (devoid of phosphates) containing phenol and 3-CBA at 2, 5, or 10 $\mathrm{mM}$ levels each. Both the gel beads had a cell population of the respective strain equivalent to a cell protein content of about $2.8 \mathrm{mg} / \mathrm{g}$ beads (wet wt.) to start with. Aeration was kept at $1 \mathrm{vvm}$ in all the experiments.
In the case of $2 \mathrm{mM}$ each of the substrates complete disappearance of phenol and 3-CBA occurred at 6 and 7 $\mathrm{h}$, respectively (Figure 2). Release of stoichiometric amounts of $\mathrm{Cl}^{-}$was observed within $8 \mathrm{~h}$. Leaching of cells to the medium was minimal, the total free cells observed being equivalent of $0.06 \mathrm{mg}$ protein $/ \mathrm{ml}$ at $8 \mathrm{~h}$. The medium containing $5 \mathrm{mM}$ each of phenol and 3-CBA was inoculated with the same beads used in the case of $2 \mathrm{mM}$ batch, after washing them with the medium. Now, the beads contained $2.4 \mathrm{mg}$ cell protein $/ \mathrm{g}$ beads (wet wt.). There was an initial steep decrease in concentrations of both the substrates until $6 \mathrm{~h}$, followed by a slackening until about $20 \mathrm{~h}$. After that the disappearance was faster and complete degradation of phenol occurred within $25 \mathrm{~h}$, while 3-CBA disappeared in $28 \mathrm{~h}$ (Figure 3). Release of stoichiometric amounts of $\mathrm{Cl}^{-}$from 3-CBA was noticed at $30 \mathrm{~h}$. Leaching of cells was minimal and the maximum amount of free cells observed in the medium was equivalent to $0.11 \mathrm{mg}$ protein $/ \mathrm{mL}$. The beads recovered from the $5 \mathrm{mM}$ batch containing $2.1 \mathrm{mg}$ cell protein $/ \mathrm{g}$ beads (wet wt.) were inoculated into the $10 \mathrm{mM}$ batch. With $10 \mathrm{mM}$ each of the substrates the pattern of their disappearance was similar to that of lower concentrations and complete disappearance of phenol and 3-CBA occurred at 66 and $72 \mathrm{~h}$, respectively (Figure 4). The medium started turning slightly brownish after about $8 \mathrm{~h}$ and the colour deepened slightly with time and remained until the end of the experiment (not shown in the Figure). This colour formation was due to the accumulation and auto-oxidation of 3-CC, the intermediary metabolite of 3CBA degradation (Ajith-Kumar and Kunhi, 2000; Jayachandran and Kunhi, 2009). The $\mathrm{Cl}^{-}$released at $24 \mathrm{~h}$ was about $40 \%$, which increased to only $86 \%$ even after $78 \mathrm{~h}$ and did not show any further increase. The cells leached and grown in the medium at $78 \mathrm{~h}$ was equivalent of about $0.145 \mathrm{mg}$ protein $/ \mathrm{mL}$.

Figure 2: Simultaneous degradation of $2 \mathrm{mM}$ each of

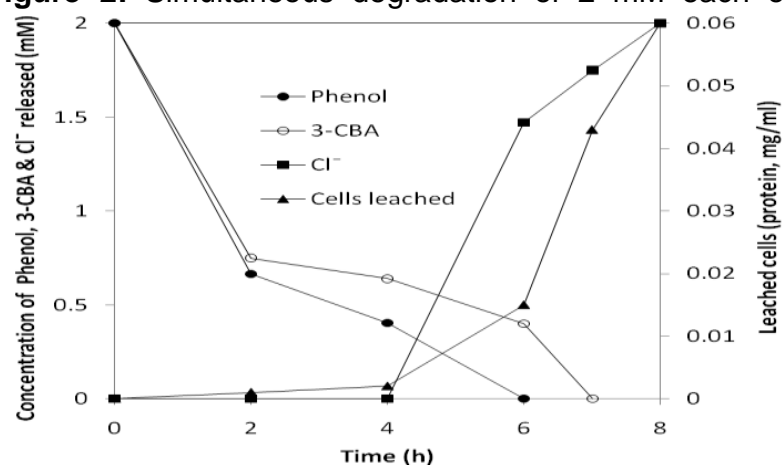

phenol and 3-CBA by a mixture of $20 \mathrm{~g}$ each of gel beads of Ca-alginate-entrapped cells of Pseudomonas sp. CP4 and $P$. aeruginosa $3 \mathrm{mT}$ in $500 \mathrm{~mL}$ phosphate-free $\mathrm{M} 3$ mineral medium in a fluidized bed bioreactor aerated by sparging sterile compressed air at $1 \mathrm{vvm}$. Other details are as in "Methods". 


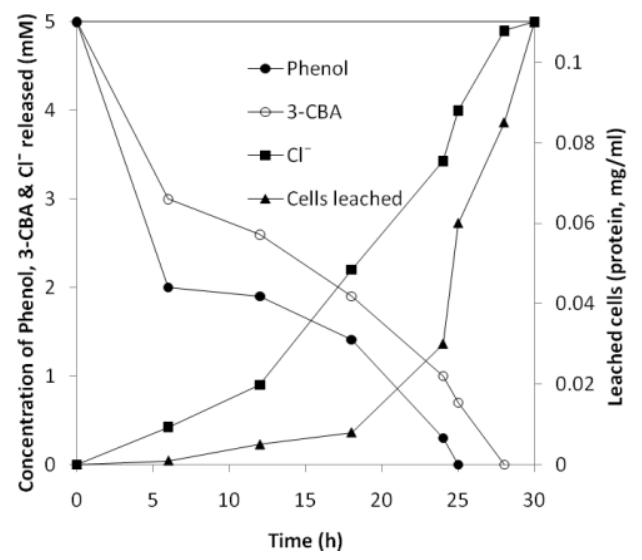

Figure 3: Degradation of a mixture of $5 \mathrm{mM}$ each of phenol and 3-CBA simultaneously by a mixture of $\mathrm{Ca}$ alginate-entrapped cells of Pseudomonas sp. CP4 and $P$. aeruginosa $3 \mathrm{mT}$ ( $20 \mathrm{~g}$ each of gel beads) in $500 \mathrm{~mL}$ phosphate-free M3 mineral medium in a fluidized bed bioreactor aerated by sparging sterile compressed air at 1 vvm. Other details are as in "Methods".

With all the 3 concentrations an initial sharp decline in both the substrates was observed (Figures 2, 3 and 4) which could be due to the adsorption or biosorption of the substrates to the gel or the bacterial cells. Such a phenomenon of reaching the adsorption/biosorption equilibrium at early hours of incubation has been demonstrated in several cases (Aksu, 2005). In our previous studies on simultaneous degradation of phenol/3-CBA mixture by a mixed culture of free cells of strains of SPC-2 and $3 \mathrm{mT}$ in shake flasks also such a phenomenon was observed (Jayachandran and Kunhi, 2009).

\section{DISCUSSION}

Simultaneous degradation of chlorinated- and nonchlorinated aromatic compounds generally is not effective due to the biochemical incompatibility. However, we have reported earlier that a mixed culture containing free cells of strains CP4 and 3mT could efficiently degrade a phenol-3-CBA mixture (Babu et al., 1995a). Similarly, a mixed culture of strains $3 \mathrm{mT}$ and $P$. stutzeri SPC-2, another phenol-degrader with an ortho-pathway also was shown to degrade both these substrates simultaneously (Jayachandran and Kunhi, 2009). However, there seems to be no report on degradation of these two compounds simultaneously by immobilized cells of any organisms, although there have been several reports of degradation of phenol (Agarry et al., 2008; Ahamad and Kunhi, 2011) and a few reports on catabolism of 3-CBA (Sahasrabudhe et al., 1991; Yun et al., 2009) separately by immobilized microbes. In the present study, the complete disappearance of $2 \mathrm{mM}$ each of phenol and 3-CBA occurred within 6 and $7 \mathrm{~h}$, respectively with the release of stoichiometric amounts of $\mathrm{Cl}^{-}$whereas with free cells the disappearance of the same amounts of substrates took

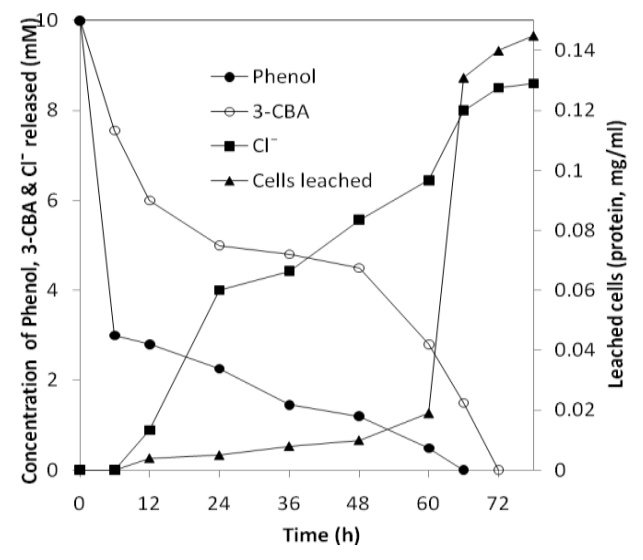

Figure 4: Degradation pattern of $10 \mathrm{mM}$ each of phenol and 3-CBA mixture by a mixture of Ca-alginate-entrapped cells of Pseudomonas sp. CP4 and $P$. aeruginosa $3 \mathrm{mT}$ (20 g each of beads) in $500 \mathrm{~mL}$ phosphate-free M3 mineral medium in a fluidized bed bioreactor aerated by sparging sterile compressed air at $1 \mathrm{vvm}$. Other details are as in "Methods".

more than $9 \mathrm{~h}$ and the complete mineralization with the release of stoichiometric amount of $\mathrm{Cl}^{-}$took about $24 \mathrm{~h}$ (Babu et al., 1995a). Degradation of same amounts of the substrates by free cells of a mixed culture of strains $3 \mathrm{mT}$ and SPC-2 also took more than $24 \mathrm{~h}$ (Jayachandran and Kunhi, 2009). Both those studies, however, were conducted in shake flasks and the inoculum levels were lower than that were used in the present immobilized system. Nevertheless, much improved tolerance and degradation of phenol (as a single substrate) was observed when immobilized cells of strain CP4 were used, as compared to the free cells of the same, in a fluidized bed bioreactor under similar conditions (Ahamad and Kunhi, 2011). Free cells could degrade only $1000 \mathrm{mg} / \mathrm{L}$ of phenol in the bioreactor whereas the Ca-alginate entrapped cells were able to degrade $1500 \mathrm{mg} / \mathrm{L}$. Agar gel entrapped CP4 was far superior in tolerating and degrading phenol at much higher concentrations up to $3000 \mathrm{mg} / \mathrm{L}$. The time taken for complete degradation of phenol (as a single substrate) at 500, 1000, 1500, 2000, 2500 , and $3000 \mathrm{mg} / \mathrm{L}$ by agar-entrapped cells were 14, $34,35,72,90$, and $135 \mathrm{~h}$, respectively (Ahamad and Kunhi, 2011). In the present case 5 and $10 \mathrm{mM}$ (i.e. 470.55 and $941.1 \mathrm{mg} / \mathrm{L}$ ) phenol in the equimolar mixture was degraded within 25 and $66 \mathrm{~h}$, respectively (Figures 3 and 4) whereas the mixed culture in free suspended form in shake flasks took 48 and $90 \mathrm{~h}$ to reach maximum growth indicating complete utilization of 5 and $10 \mathrm{mM}$ phenol in equimolar mixtures (Babu et al., 1995a).

3-CBA from a $5 \mathrm{mM}$ equimolar mixture disappeared in $28 \mathrm{~h}$ and complete mineralization occurred at $30 \mathrm{~h}$ as indicated by $100 \%$ release of $\mathrm{Cl}^{-}$(Figure 3). In the case of $10 \mathrm{mM}$ equimolar mixture, although 3-CBA completely disappeared from the medium at $72 \mathrm{~h}$, complete mineralization did not occur as indicated by accumulation of $3-\mathrm{CC}$ and release of only $86 \%$ of $\mathrm{Cl}^{-}$(Figure 4). There 
are only a few reports on degradation of chlorobenzoates by immobilized systems. Sahasrabudhe et al. (1991) have reported dehalogenation of mixtures of monochlorobenzoates and 2, 4-dichlorophenoxyacetic acid by Ca-alginate entrapped cells of Pseudomonas sp. US1 ex, the rates of dehalogenation being comparable to that of free cells. Recently, Yun et al. (2009) have made a comparative study of degradation of 3-CBA by free and polymer-entrapped cells of Rhodococcus erythropolis strain S-7. They used Ca-alginate $(C A)$, polyvinyl alcohol (PVA), and combinations of PVA-CA and chitosan-CA for entrapment of the cells. CA alone or PVA alone were found to be not suitable as the beads disintegrated in the former case and the cells got disrupted in the latter case. However, PVA-CA and chitosan-CA gels were found to be stronger and the former being better in terms of oxygen transfer. $200 \mathrm{mg} / \mathrm{L}$ of 3-CBA was degraded within $60 \mathrm{~h}$ by free cells as well as by the cells entrapped in these combination gels, PVA-CA being slightly better. Disruption of the beads in media containing phosphates is well known and that was the reason why M3 medium devoid of phosphates was used in the present study as described previously (Ahamad and Kunhi, 2011). We have also observed earlier that agar gel was far superior as a cellentrapment matrix in the case of phenol degradation, in terms of gel strength, tolerance to higher concentration of the substrate and the rate of degradation (Ahamad and Kunhi, 2011). In the present study, being a preliminary one, alginate was chosen because it entraps whole cells under mild conditions. It would be worthwhile making a comparative study of different gels for entrapment so as to improve the degradation of phenol/3-CBA mixtures simultaneously.

This seems to be first study where 2 different organisms following 2 different ring-cleavage modes were separately immobilized and used as a mixed culture for simultaneous degradation of phenol and 3-CBA. There have been, however, a few reports on simultaneous degradation of phenol and other chloroaromatics such as chlorophenols by immobilized systems (Menke and Rehm, 1992). They immobilized the cells of Alcaligenes sp. A7-2 as a biofilm on lava that was used as a filling material in the packed-bed reactors. Degradation patterns obtained with immobilized cells were comparable with that of free cells in batch culture. The continuous cultures remained stable despite increasing the input rates of chlorophenol and phenol mixtures up to $1.16 \mathrm{mM} / \mathrm{L} / \mathrm{h}$ for several weeks.

Repeated usability is one of the important advantages of immobilized systems. In the present case after repeated use with increasing equimolar concentrations of the substrates the cell-immobilized beads were found to be active, although there was a slight decrease in the cell populations in the beads i.e. the initial $2.8 \mathrm{mg}$ protein $/ \mathrm{g}$ beads decreased to less than $2.0 \mathrm{mg}$ protein $/ \mathrm{g}$ beads after the third run with $10 \mathrm{mM}$ each of substrate. This could be because the medium was devoid of phosphates which are required for the active growth of the cells. Similar phenomenon was observed with $\mathrm{Ca}$-alginate entrapped CP4 when used repeatedly with increasing concentrations of phenol in M3 medium without phosphates (Ahamad and
Kunhi, 2011). On the contrary, a slight gain in the cell content was observed, even after 6 passages through increasing concentration of 500 through $3000 \mathrm{mg} / \mathrm{L}$ phenol, when agar beads were used (Ahamad and Kunhi, 2011). Mukherjee-Dhar et al. (1998) have reported 3 successive uses of Ca-alginate immobilized cells of Rhodococcus opacus strain TSP203 in batch cultures for the degradation of trichloro-, tetrachloro-, and pentachlorobiphenyls with decreasing degrees of efficiency while free cells in solution lysed after the first use itself. Although Ca-alginate afforded protection against toxicity of PCBs, they were also unable to obtain a stable regeneration of the biocatalyst, probably, due to the absence of phosphate in the medium that they also used. It is possible that entrapment in agar gel or PVA-CA, which provides better gel strength and makes it possible to use in phosphate-containing medium, may improve the degrading ability of both CP4 and 3mT strains, but needs to be verified experimentally.

In conclusion it could be said that Pseudomonas sp. CP4 (that degrades phenol/cresol isomers through metapathways) and $P$. aeruginosa $3 \mathrm{mT}$ (that degrades 3CBA/4-CBA through a modified ortho-pathway) immobilized separately by encapsulation in Ca-alginate when used as a mixture exhibited more effective degradation of phenol-3-CBA mixtures than by their free cells. However, use of a medium devoid of phosphates to avoid the disintegration of the gel beads seems to be a drawback with respect to their repeated usability. This could be overcome by using alternate gel matrices such as agar gel or modified alginate gel such as PVA-CA which has been shown to be superior. Both the strains CP4 and 3mT have been shown to degrade other aromatic compounds besides being very efficient degraders of their respective substrates. Strain CP4 could effectively mineralize all 3 isomers of cresol, creosote, aniline, benzoate, 3-hydroxy and 4-hydroxybenzoates, catechol, 4-methyl catechol, gentisate, protocatechuate etc. besides degrading phenol at high concentrations (Babu et al., 1995a; 1995b; Ahamad and Kunhi, 1999; Ahamad et al., 2001, Ahamad and Kunhi, 2011). Strain $3 \mathrm{mT}$ is capable of degrading various aromatic compounds such as benzoates, 3- and 4-hydroxybenzoates, catechol, 3- and 4-CC etc. besides being able to degrade as much as $8 \mathrm{~g} / \mathrm{L}$ of $3-C B A$ and $12 \mathrm{~g} / \mathrm{L}$ of 4-CBA (Ajith-Kumar and Kunhi, 2000). This strain has also proved to be an effective partner with both a meta-cleaving phenol degrader strain CP4 and an ortho-cleaving phenol degrader strain SPC-2 for simultaneous degradation of phenol-3-CBA mixtures (Babu et al., 1995a; Jayachandran and Kunhi, 2009). This strain also was shown to bioremediate effectively soils contaminated with 3-chloro and 4-chlorobenzoates, thus eliminating their toxicity and helping the germination of tomato seeds (Ajith-Kumar et al., 1998). All these positive attributes and the results of this study indicate a clear possibility of deploying immobilized cells of these strains for simultaneous degradation of heterogeneous mixtures of phenol/cresol isomers, 3-CBA/4-CBA and other aromatics. However, further detailed studies are needed to select 
suitable gel matrices and optimization of cultural and bioreactor conditions, before a viable treatment technology could be developed.

\section{ACKNOWLEDGEMENT}

The authors wish to thank the Director, Central Food Technological Research Institute, Mysore, India for the facilities and for the permission to publish the data. Authors gratefully acknowledge the help rendered by Abdul Basheer in the preparation of the figures. PYAA also gratefully acknowledges the award of a Senior Research Fellowship by the Council of Scientific and Industrial Research, Government of India.

\section{REFERENCES}

Agarry, S. E., Durojaiye, A. O. and Solomon, B. O. (2008). Microbial degradation of phenols: A review. International Journal of Environment and Pollution 32, 12-28.

Ahamad, P. Y. A. and Kunhi, A. A. M. (1996). Degradation of phenol through ortho-cleavage pathway by Pseudomonas stutzeri strain SPC-2. Letters in Applied Microbiology 22, 26-29.

Ahamad, P. Y. A. and Kunhi, A. A. M. (1999). Degradation of high concentrations of cresols by Pseudomonas sp. CP4. World Journal of Microbiology and Biotechnology 15, 281-283.

Ahamad, P. Y. A., Kunhi, A. A. M. and Divakar, S. (2001). New metabolic pathway for o-cresol degradation by Pseudomonas sp. CP4 as evidenced by 'H NMR spectroscopic studies. World Journal of Microbiology and Biotechnology 17, 371-377.

Ahamad, P. Y. A. and Kunhi, A. A. M. (2011). Enhanced degradation of phenol by Pseudomonas sp. CP4 entrapped in agar and calcium alginate beads in batch and continuous processes. Biodegradation 22, 253-265.

Ajith-Kumar, P. V. and Kunhi, A. A. M. (1997). Biochemical and genetic aspects of microbial degradation of chlorobenzoates. In: Recent Advances in Ecobiological Research, Vol. 1. Sinha, M.P. (ed.). APH Publishing Corporation, New Delhi. pp. 253-269.

Ajith-Kumar, P. V., Gangadhara, K. P., Manilal, P. and Kunhi, A. A. M. (1998). Soil inoculation with Pseudomonas aeruginosa $3 \mathrm{mT}$ eliminates the inhibitory effect of 3-chloro- and 4-chlorobenzoate on tomato seed germination. Soil Biology and Biochemistry 30, 1053-1059.

Ajith-Kumar, P. V. and Kunhi, A. A. M. (2000). Pathways for 3-chloro- and 4-chlorobenzoate degradation in Pseudomonas aeruginosa $3 \mathrm{mT}$. Biodegradation 11, 247-261.

Aksu, Z. (2005). Application of biosorption for the removal of organic pollutants: A review. Process Biochemistry 40, 997-1026.

Babu, K. S., Ajith-Kumar, P. V. and Kunhi, A. A. M. (1995a). Simultaneous degradation of 3 - chlorobenzoate and phenolic compounds by a defined mixed culture of Pseudomonas spp. World Journal of Microbiology and Biotechnology 11, 148-152.

Babu, K. S., Ajith-Kumar, P. V. and Kunhi, A. A. M. (1995b). Mineralization of phenol and its derivatives by Pseudomonas sp. strain CP4. World Journal of Microbiology and Biotechnology 11, 661-664.

Bartels, I., Knackmuss, H-J. and Reineke, W. (1984). Suicide inactivation of catechol 2, 3-dioxygenase from Pseudomonas putida mt-2 by 3-halocatechols. Applied and Environmental Microbiology 47, 500-505.

Basha, K. M., Rajendran, A. and Thangavelu, V. (2010). Recent advances in the biodegradation of phenol: A review. Asian Journal of Experimental Biological Sciences 1, 219-234.

Bergmann, J. G. and Sanik, J. Jr. (1957). Determination of trace amounts of chlorine in naphtha. Analytical Chemistry 29, 241-243.

Brar, S. K., Verma, M., Surampalli, R. Y., Misra, S., Tyagi, R. D., Meunier, N. and et Blais, J-F. (2006). Bioremediation of hazardous wastes - A review. Practice Periodical of Hazardous, Toxic, and Radioactive Waste Management 10, 59-72.

Cassidy, M. B., Lee, H. and Trevors, J. T. (1996). Environmental applications of immobilized microbial cells: A review. Journal of Industrial Microbiology and Biotechnology 16, 1367-5435.

Chaudhry, G. R. and Chapalamadugu, S. (1991). Biodegradation of halogenated organic compounds. Microbiology Reviews 55, 59-79.

Dorn, E. and Knackmuss, H-J. (1978). Chemical structure and biodegradability of halogenated aromatic compounds - Substituent effects on 1,2dioxygenation of catechol. Biochemical Journal 174, 85-94.

Fetzner, S. (1998). Bacterial dehalogenation. Applied Microbiology and Biotechnology 50, 633-657.

Franck-Mokroß, A. C. and Schmidt, E. (1998). Simultaneous degradation of chloro- and methylsubstituted aromatic compounds: Competition between Pseudomonas strains using the ortho- and meta-pathway or the ortho-pathway exclusively. Applied Microbiology and Biotechnology 50, 233-240.

Jayachandran, P. V. and Kunhi, A. A. M. (2009). Degradation of 3 -chlorobenzoate and phenol singly and in mixture by a mixed culture of two orthopathway-following Pseudomonas strains. Journal of Industrial Microbiology and Biotechnology 36, 219-227.

Kaschabek, S. R., Kasberg, T., Muller, D., Mars, A. E., Janssen, D. B. and Reineke, W. (1998). Degradation of chloroaromatics: Purification and characterization of a novel type of chlorocatechol 2, 3-dioxygenase of Pseudomonas putida GJ31. Journal of Bacteriology 180, 296-302.

Keweloh, H., Heipieper, H-J. and Rehm, H-J. (1989). Protection of bacteria against toxicity of phenol by 
immobilization in calcium alginate. Applied Microbiology and Biotechnology 31, 383-389.

Lacoste, R. J., Venable, S. H. and Stone, J. C. (1959). Modified 4-aminoantipyrene colorimetric method for phenols. Application to an acrylic monomer. Analytical Chemistry 31, 1246-1249.

Lowry, O. H., Rosebrough, N. J., Farr, A. L. and Randall, R. J. (1951). Protein measurement with the Folin phenol reagent. Journal of Biological Chemistry 193, 265-275.

Menke, B. and Rehm, H-J. (1992). Degradation of mixtures of monochlorophenols and phenol as substrates for free and immobilized cells of Alcaligenes sp. A7-2. Applied Microbiology and Biotechnology 37, 655-661.

Mukerjee-Dhar, G., Shimura, M. and Kimbara, K. (1998). Degradation of polychlorinated biphenyl by cells of Rhodococcus opacus strain TSP203 immobilized in alginate and in solution. Enzyme and Microbial Technology 23, 34-41.

Sahasrabudhe, A., Pande, A. and Modi, V. (1991). Dehalogenation of a mixture of chloroaromatics by immobilized Pseudomonas sp. US1 ex cells. Applied Microbiology and Biotechnology 35, 830-832.

Vidali, M. (2001). Bioremediation. An overview. Pure and Applied Chemistry 73, 1163-1172.

Yun, Q., Lin, Z. and Xin, T. (2009). Cometabolism and immobilized degradation of monochlorobenzoate by Rhodococcus erythropolis. African Journal of Microbiology Research 3, 482-486. 